\title{
DIFERENTES MIRADAS SOBRE LA SOCIEDAD POR ACCIONES SIMPLIFICADA (SAS) Tras un nuevo conocimiento*
}

\author{
Ruby Stella Jaramillo Marín ${ }^{1}$
}

\section{RESUMEN}

La Sociedad por Acciones Simplificadas deviene principalmente del derecho francés. Este prototipo ha tenido gran acogida en diversos países, debido a la gran facilidad de adaptarse a las diferentes exigencias y necesidades de los Empresarios. En Colombia la SAS fue creada por medio de la Ley 1258 de 2008, y al igual que en otros países como se mencionaba, ha sido implementada debido a su simplicidad al momento de constituirse, así mismo puede realizarse a través de documento privado, este modelo dota de amplia libertad a los socios, para que estos ajusten el modelo societario conforme a sus requerimientos.

De cualquier modo debido a esta flexibilidad, libertad y bajo control al que son sometidas, se han evidenciado circunstancias negativas en el desarrollo e implementación de este modelo societario en el país debido a la inadecuada y equivocada implementación que se le está dando al ser utilizada como fachada para la ejecución de actividades ilícitas, para la evasión de tributos al Estado y la responsabilidad a cargo de cualquier sociedad en cuanto a la evasión de seguridad social de sus empleados.

\section{PALABRAS CLAVES}

Sociedad, acciones, socios, Tributos, simplificada.

\begin{abstract}
The Joint Stock Companies come mainly from the French Law. This prototype has been welcome in different countries due to the capacity to adapt with ease to different demands and needs of the entrepreneurs. In Colombia the JSC was created through the act 1258 in 2008, and just like in other countries, it has been implemented due to its simplicity at the moment of its constitution, in like manner, it can be made through a private document, this model offers freedom to the partners so they can use the corporate model according to its requirements.
\end{abstract}

In any case, due to this flexibility, freedom and low control they are submitted to, some negative circumstances have emerged in the development and usage of this corporate model in the country due to the inadequate and wrong implementation when used as a façade for the execution of illegal activities with the purpose of tax evasion and the responsibility in charge of any society as far as the evasion of social security of its employees.

\section{KEYWORDS}

Society, Stocks, Partners, Flexibility, Taxes, Simplified.

Depositado en agosto 15 de 2014, aprobado en octubre 31 de 2014.

* El presente artículo es el resultado del informe final del proyecto de investigación Responsabilidad fiscal de las sociedades por acciones simplificadas frente a la ley 1258 de 2008.

1 Abogada de la Universidad Católica de Colombia. Especialista en Derecho Tributario y Aduanero, Magister en Derecho Internacional y Derechos Humanos, Candidata a Doctora de la Universidad Iberoamericana de México. Docente de la Universidad Autónoma de Colombia. Directora del semillero de investigación "Tras un nuevo conocimiento" de la Universidad Autónoma de Colombia. 


\section{INTRODUCCIÓN}

Contrario sensu se ha escrito bastante sobre los aspectos positivos y los diferentes beneficios que trae consigo la Sociedad por Acciones Simplificadas, y de forma especial lo han hecho quienes fueron participes en su creación, mediante la Ley 1258 de 2008.

A contrario sensu se ha escrito muy poco sobre los aspectos negativos de este tipo societario y de las posibles implicaciones perjudiciales a nivel legal que trae consigo la flexibilidad contenida en esta Ley, cuya preponderancia consiste en dejar amplia libertad a sus accionistas, para que en tal sentido estos acoplen el modelo societario a sus necesidades, a sus posibilidades y a las actividades que pretenden desarrollar a través de ésta.

Se hace entonces necesario dar una mirada más a fondo sobre las Sociedades por Acciones Simplificadas, para así analizar los diferentes puntos nocivos y dañinos, que ya se han venido presentando desde el año 2008 en el que fue creado este tipo societario. Se parte de la base de que este estándar societario es un tipo de sociedad nuevo y diferente, aunque si bien comparte determinados aspectos y elementos de los modelos societarios tradicionales anteriormente constituidos, como las sociedades anónimas y las sociedades de responsabilidad limitada, su diferencia radica en su carácter propio de flexibilidad, libertad, la regulación a la que son sometidas y los alcances que se derivan de los anteriores aspectos.

Así que podría decirse que la SAS fue diseñada no solo, para actividades tradicionales, sino principalmente para actividades económicas actuales, que han surgido del avance y la evolución de las operaciones económicas. Por tanto, se trata de una figura societaria moderna, que ha causado gran impacto, en variedad de países que han implementado este estándar societario, incluyendo a Colombia, la que ha sufrido una gran proliferación de Sociedades por Acciones Simplificadas.

\footnotetext{
2 Colombia. Ley 599 de 2000. Código Penal Colombiano.

3 Colombia. Estatuto Tributario 2009 al 2014.
}

Debido a esta expansión de SAS que ha experimentado el país, es preciso realizar un análisis concreto de las implicaciones perjudiciales que trae consigo este prototipo societario.

Como corolario de lo anterior, se puede citar la adaptación de arquetipos extranjeros avanzados, con contextos jurídicos desarrollados y adelantados que no encajan con propiedad y precisión en tipos societarios y jurídicos en desarrollo.

Este tipo societario es utilizado como fachada para la ejecución de actividades ilícitas ${ }^{2}$, debido a su flexibilidad y a su bajo control por parte de las autoridades encargadas de tal gestión; en donde el patrón societario se utiliza para evadir tributos al Estado ${ }^{3}$ y la responsabilidad que trae consigo una sociedad en cuanto a la evasión de seguridad social a sus empleados, entre otros. Aspectos que sin duda dejan entre ver los grandes alcances que pueden tener la SAS, y que deben ser tratados con mayor atención y precaución.

\section{DIFERENTES MIRADAS SOBRE LA SO- CIEDAD POR ACCIONES SIMPLIFICA- DA (SAS)}

\section{ANTECEDENTES DE LA SOCIEDAD POR ACCIONES SIMPLIFICADA}

Para empezar debe decirse que existen tres elementos que caracterizan a las legislaciones que permiten la creación o constitución de sociedades, la primera de ellas radica en que el régimen legal posee un sistema de limitación de responsabilidad de los asociados, la segunda determina la existencia de un régimen tributario claro y con nivel único de imposición y la tercera y última compuesta por una amplia libertad contractual que favorece la creatividad e iniciativa de ideas privadas.

Sin embargo, nada de lo anterior se apreciaba antes la implementación de la Sociedad por Acciones Simplificada, ya que los impuestos eran altamente inestables y la flexibilidad contractual 
era menos notoria, lo que evidenciaba un atraso en nuestro país. Es gracias a esto que nacen los mercados con leyes para sociedades cuya finalidad era la de actualizar las reglas, para que de tal forma se evitara el desplazamiento e incursión de empresarios hacía naciones con modelos más flexibles para crear sociedad.

Con la evolución del mundo contemporáneo se impone la adopción de formas asociativas con una estipulación contractual propia y flexible; no obstante, es importante mencionar que el ser humano desde sus orígenes ha tenido la necesidad de asociarse o de unirse para un fin común, esto cuando los diferentes esfuerzos individuales y aislados no eran suficientes para la supervivencia, lo que obligó al hombre como individuo a agruparse y a unir sus esfuerzos para alcanzar sus metas, lo que originó una evolución inseparable para la condición del ser humano.

Esta unión de fuerzas produjo una manifestación en todas las épocas a diferente escala, a través de la actividad humana, desde el trabajo manual, industrial, intelectual, hasta el trabajo comercial. Un ejemplo de lo anterior es el surgimiento de sociedad en la edad media, en la que aparece la necesidad de asociarse con el objetivo de perpetuar o continuar el legado de autoridad del Pater Familias, conformándose así la sociedad civil, que tenía como legado el fortalecimiento y la conservación de la estructura familiar pese al fallecimiento del líder familiar como lo es el Pater familia. Sociedad que preservaba el fundamento de persona, lo que se conoce como el inicio de intuito personae.

Lo curioso es que con el desarrollo del comercio las necesidades comenzaron a cambiar, así que el fin de la sociedad civil se enfocó en el aspecto económico, tanto así que ya no sólo la familia conformaba la sociedad si no que implementaron la incursión de personas ajenas a la familia. Se realizaba intercambio de bienes, lo que dio como resultado las primeras sociedades de tipo mercantil. Esto constituyó la necesidad de asociación con fines lucrativos, de la que nace posteriormente la sociedad anónima desarrollada en principio en Gran Bretaña e impulsada continuamente en Estados Unidos.
De otro lado la sociedad colectiva fue afrontada por las "Ordenanza del Comercio" francesa (1673), denominándola general o libre, en la que se entendía la sociedad como un contrato en el cual era indispensable la pluralidad de sujetos. Ya en 1808 el Código de Comercio Francés, diferenció las sociedades colectivas (personas) de las sociedades de capital, lo que produjo la inserción del concepto de empresa y de sociedad anónima y surge como código independiente del código civil.

Aproximadamente noventa años después la Ley alemana (1892) desarrolla la sociedad de responsabilidad limitada, apta para pequeños y medianos empresarios. Estados Unidos igualmente introdujo en década de los 90s la sociedad limitada, en esta las personas tienen limitación en la responsabilidad y ha sido exitosa debido a esta limitación plena que la legislación les garantiza a sus asociados.

Mientas que en América latina se enfocaban en mirar problemáticas como la imposibilidad de sociedades unipersonales, la existencia de revisores fiscales, supervisores, entre otros desviándose así la atención para promover la creación de nuevas empresas y así contribuir al crecimiento económico y bienestar general.

\section{ANTECEDENTES EN DERECHO COM- PARADO}

En las diferentes clases de sociedad, pareciera existir una tendencia entre los sistemas jurídicos anglosajones y los tradicionales civilistas, las cuales tienen una estrecha relación con elementos personalistas, que resultan ser una invención americana durante los años sesenta.

Los países del mundo Romano-Germánico, han tenido un gran avance en la regulación de las sociedades constituidas. Debido a esto algunos países de Europa han adoptado tipos de sociedad mezclados. Así que estos países acogieron la normatividad de países en los que se practicaba o acogía el Common Law. No obstante, los países de tradición civilista intentan aproximarse a los del sistema anglosajón, a través del acogimiento de reformas relacionadas con el gobierno, el cual introdujo normas sofistica- 
das, diseñadas para la inversión privada. Esto propició confianza en los inversionistas en lo referente al mercado de valores y en la corrección de las deficiencias de los administradores de grades compañías, situaciones que han impulsado al gobierno corporativo, en los países de concepción civilista y así mismo lo del Common Law.

La innovación del sistema jurídico, que pretendió la modernización y flexibilización del sistema societario fueron entorpecidos en el pasado, han encontrado nuevos caminos para lograr la naturaleza contractual de las nuevas formas societarias. Como resultado en materia de sociedades en Asia, Europa y América Latina, se ven cada vez más influenciadas por el derecho anglosajón. Este método legislativo, logra llevar a que los países de anglosajones superen a los de tradición romano-germánica, en lo que tiene que ver con la innovación jurídica y desarrollo económico.

\section{- Legislación Estadounidense}

La primera fuente de los nuevos tipos de sociedad se encuentra en el desarrollo del Derecho societario Estadounidense, en lo que tiene que ver con sociedades de personas y de responsabilidad limitada. Estos asumieron una disciplina especial amplísima de la libertad contractual y por la defensa del principio de limitación de riesgos asociados.

La sociedad de responsabilidad limitada (LLC), perteneciente al sistema Estadounidense, nació como un intento para evitar el sistema de doble tributación, perteneciente a las sociedades de capital. Por lo que se expidieron normas semejantes a las existentes en América Latina, hasta el punto de darle a estas sociedades la amplísima flexibilización para los empresarios.

Este modelo combina las ventajas de la limitación de la responsabilidad con una estructura flexible de gobierno corporativo y un trato preferencial en materia tributaria. Por otro lado proporciona la disminución de producción de procedimientos legales para la constitución y funcionamiento de la sociedad, en comparación con las otras sociedades. Se determinó como una sociedad personalista para efectos fiscales y en consecuencia no podía ser gravada a dos niveles, como las sociedades de capital. Lo que dio lugar a una expansión definitiva de la sociedad capitalista cerrada LLC. Los demás estados de la Unión Americana lentamente comenzaron a adoptar legislaciones relativas a esta clase de sociedad.

En el año de 1997 se expidió una nueva normatividad, en la que cualquier sociedad que se haya constituido bajo un régimen diferente al de la sociedad de capital tradicional, estará sujeta al régimen fiscal aplicable a las sociedades de personas. Esta sólo constituye un número de individuos asociados, los cuales redistribuyen entre si los beneficios económicos obtenidos, por lo que las utilidades distribuidas por una LLC se tratan fiscalmente como si hubiesen sido un ingreso obtenido directamente por los socios individualmente considerados. Cosa contraria sucede con las sociedades de capital tradicionales, las cuales son unidades sociales que se someten al régimen de doble tributación, de tal forma que los ingresos se gravan en primer lugar en la sociedad y después en cabeza de los accionistas individualmente.

- Legislación Francesa sobre La Sociedad por Acciones Simplificadas

Ya hace más de una década se implementó en Francia la sociedad por acciones simplificada. Desde la expedición de la Ley del 3 de enero de 1994, esta clase de sociedad ha superado de forma importante el resto de sociedades, con excepción a la sociedad de responsabilidad limitada.

En tal medida el sistema societario francés ha evolucionado positivamente, claro que tal cambio no fue de la noche a la mañana, sino que ha sido el recorrido de un devenir histórico, con una estrecha relación con la libertad de establecimiento de las sociedades dentro del territorio de la Unión Europea.

El modelo societario de la SAS en Francia se diferencia del modelo colombiano, en que en Colombia este modelo desde el principio se incluyeron todas las innovaciones al momento de su creación, mientras que la fórmula de la SAS en Francia ha sufrido grandes cambios debido a diversas modificaciones, con el propósito de 
hacerlo más flexible, convirtiéndolo en una figura versátil.

Como característica importante se encuentra que estas sociedades, es que su regulación queda sujete a las pautas contractuales que sus asociados escojan. El legislador lo que pretendió relevar a los empresarios que la implementen de la rigidez normativa.

Legislación Chilena sobre La Sociedad por Acciones Simplificadas

El primer avance trascendental en Chile lo marcó la adopción de la denominada empresa individual de responsabilidad limitada, mediante la Ley 19.857 de $2003^{4}$, la cual permitió habituar el concepto de unipersonalidad en el ámbito jurídico chileno, y facilitó la adopción de normas posteriores relacionadas con este tema. En el año de 2007, en Chile se expidió le Ley $20.190^{5}$ sobre reformas tributarias e institucionales para el fomento de la industria de capital y la modernización del mercado de capitales. La creación de tal norma buscaba la facilitación en la creación de compañías de capital de riesgo para proponer la innovación y el desarrollo de nuevos productos, es decir, que buscaban mayor flexibilidad en la forma societaria en la industria de capitales de riesgo, suplidas a través de mecanismos legales que buscaban superar dificultades, por medio de pactos privados.

La normatividad chilena se caracteriza por la gran flexibilidad del tipo. La sencillez de su regulación, que se manifiesta en una amplia libertad contractual, lo que facilita la asociación de capital e industria y la financiación de nuevos proyectos. La ley 20.190 define la sociedad por acciones como una persona jurídica, la cual es creada por una o más personas, a través de un acto de constitución, cuya participación en el capital es representada por acciones, de la misma manera data que la sociedad tendrá uno estatuto social, en el que se establecen los derechos y obligaciones de los accionistas, el régimen de administración y los demás pactos que podrán ser establecidos libremente.

Legislación Brasileña sobre La Sociedad por Acciones Simplificadas

En el sistema brasileño se evidencia la gran influencia del Decreto Estadounidense de sociedades. En Brasil no se ha expedido una Ley especifica que regule formas híbridas de sociedad. No se ha creado una sociedad por acciones simplificadas, ni la sociedad colectiva de responsabilidad limitada. Sin embargo el Código Civil brasileño de $2002^{6}$ instituyó, una forma asociativa denominada sociedad simple. Este tipo de compañía se diferencia de las sociedades comerciales, en que estas son personas jurídicas de Derecho Privado, con actividades inherentes a profesiones intelectuales de naturaleza científica.

La falta de un tipo social como la SAS en Brasil obliga a los asociados a afectar el tipo de sociedad anónima para incluirle elementos contractuales de naturaleza personalista.

Legislación Británica sobre Sociedades de Personas de Riesgo Limitado

La legislación Británica implemento en materia de sociedades colectivas de responsabilidad limitada. Este modelo d sociedad adopta la filosofía de las sociedades híbridas, es decir, que se trata de especies asociativas de acentuado estatus personalista, sin menoscabo en lo que tiene que ver con la limitación de la responsabilidad. Entonces, la libertad contractual es característica principal de esta clase de sociedades es la libertad contractual, otro aspecto lo constituye el marco de interés que las autoridades de Reino Unido ha desarrollado, en cuya intención se demuestra en tratar de proveer a los particulares un modelo de sociedad que pueda ser utilizado por las personas interesadas en este tipo de so-

\footnotetext{
4 Congreso Nacional de Chile. Ley 19.857 de 2003. Autoriza el establecimiento de empresas individuales de responsabilidad limitada 5 Congreso Nacional de Chile. Ley 20.190 de 2007. Introduce adecuaciones tributarias e institucionales para el fomento de la industria de capital de riesgo y continua con el proceso de modernización del mercado de capitales.

6 Ley N 10.406 del 10 de enero de 2002 (Código Civil). Contiene disposiciones sobre los contratos que se pueden extender a los contratos de propiedad intelectual.
} 
ciedades, cuando no cuentan con asesoría o con recursos.

Legislación Española Sobre Sociedades "Nueva Empresa"

Esta legislación fue objeto de una gran estructuración para hacerlo más favorable para los mediano y grandes empresario. De tal forma la competitividad obligó a la legislación española a expedir una nueva norma para así disminuir las formalidades y disminuir el ámbito de mandatos imperativos para las sociedades pequeñas. De tal forma se trata de compañías de sociedad limitada, las cuales se someten a requisitos menos estrictos, para lo que expidieron la Ley 2 de $1995^{7}$.

Como características fundamentales de esta forma de sociedad están las posibilidades de constitución unipersonal o por medio del documento único electrónico, la supresión del libro de registro de socios, la simplificación de los órganos de dirección y gestión, y la posibilidad de objeto genérico.

Entonces que este modelo de sociedad contiene aún una regulación jurídica bastante rígida, lo que no ha dejado que esta tenga un gran impacto, como en el resto de países que han implementado de una $\mathrm{u}$ otra forma este modelo.

\section{CONTEXTO DEL DERECHO SOCIETA- RIO EN AMÉRICA LATINA}

El derecho europeo ha sido la principal influencia en América Latina, en especial el Código Francés de 1808, aunque también existe influencia española del Código de 1829. Estos fueron redactados conforme a las necesidades de la sociedad y la economía para ajustarlo a estas y que acoplaran al sistema, aunque la adaptación no fue mucha, ya que la adopción es fue casi transcrito sin mayor cambio.

Abordando el tema de manera más específica, puede decirse que en lo que se refiere a Brasil, tuvo influencia del Código francés, español y portugués, lo que permitió la promulgación de su Código de comercio en 1850, y ha sido objeto de variedad de reformas. En cuanto a México se inspiró en el Código español de 1829 (Ordenanzas de Bilbao), por lo que su Código fue hecho en 1854, de la misma forma ha sufrido numerosas reformas. El Código de Argentina se fundamentó en los códigos de comercio francés, español, portugués y holandés, siendo expedido en 1859. En Chile el Código de comercio tuvo influencia del Código Español y del Código de Napoleón el cual empezó a regir en el año de $1867^{8}$.

En un sentido más actual, durante los últimos años América latina ha experimentado cambios a nivel comercial como tratados de libre comercio con EE.UU, la unión europea y otros países con el fin de promocionar el desarrollo de la región, así mismo esto con el fin de que grandes empresarios miren en territorio latinoamericano y lo vean como una buena propuesta de inversión. Sin embargo, esto no podría hacerse sin un régimen legal apropiado, pues con esto se pretende facilitar el comercio mediante el ajuste de las normas jurídicas de modo que pueda atenuarse la figura paternalista para que así pueda surgir el derecho societario en su esencia.

No obstante, no puede realizarse todo sin un previo análisis y estrategias acorde a los países latinoamericanos pues no puede implementarse los regímenes económicos de países como estados unidos y Europa cuando el contexto y circunstancias latinoamericanas son completamente distintos.

De otro lado, es evidente que el resultado del alto nivel de concentración de capital en América Latina, el control sobre los modelos societarios normalmente es ejercido por los accionistas mayoritarios presentándose así la divergencia entre los intereses de los accionistas mayoritarios con los minoritarios. Esta situación también se presenta en las sociedades de familia, en las que los miembros que tiene un capital mayor gozan de poder sobre los minoritarios, llamándosele a este el modelo tradicional.

7 Jefatura del Estado. Ley 2 de 1995. De Sociedades de Responsabilidad Limitada.

8 PINZÓN, Gabino, Derecho Comercial, Editorial Temis, Bogotá 1957, Págs. 25 y siguientes. 
Es por esto que en América Latina la mayoría de las empresas se constituyen como sociedades anónimas cerradas, debido a que los mercados son pequeños en comparación con los de las economías de mercado desarrolladas. Por tanto, se debe reconocer el problema de agencia en la organización societaria en América Latina no solo hace referencia en gran medida a los conflictos entre accionistas mayoritarios y sus contrapartes sino también a la situación específica que surge de la naturaleza cerrada de la mayoría de las empresas.

Cabe mencionar que el formalismo del derecho privado y el miedo a la modernización son grandes obstáculos que los regímenes latinoamericanos deben atravesar, aunque se presenten los conocidos problemas que representa la reforma de estatuto sistemáticos de derecho comercial, pues toda reforma siempre se enfrenta a la enorme dificultad de mantener la armonía de las novedades que se introducen con el cuerpo jurídico que ya existe, debido a que cualquier inconsistencia suscita ambigüedades interpretativas y puede dar lugar a la desarticulación de lo ya existente, por otro lado la defensa de las costumbres y de los códigos siempre constituye buen pretexto para oponerse a los intentos de reforma normativa.

Es por eso que las SAS constituyen una configuración normativa, con una estructura orgánica, con una mayor libertad de estipulación contractual y la posibilidad que tiene los accionistas de suscribir acuerdos de sindicación de acción de gran eficacia han sido concebidos para hacerles frente a las situaciones más comunes que se presentan en la economía societaria.

\section{ANTECEDENTES DE LA SOCIEDAD POR ACCIONES SIMPLIFICADA EN COLOMBIA}

Primeramente debe decirse que el Código de Comercio colombiano tiene gran influencia francesa, ya que a través de Código de Panamá se adoptó casi literal el Código de Comercio chileno, el cual fue inspirado por el Código de Comercio francés.
Como antecedentes legislativos tenemos, la legislación española con las siete partidas, la Recopilación de Indias, la Novísima Recopilación y las Ordenanzas de Bilbao de 1737.

En 1853 el Congreso de Nueva Granada expidió la primera legislación nacional sobre comercio terrestre y marítimo, éste derogó las ordenanzas de Bilbao (1737), cual fue una copia del Código Español de 1829

Posteriormente como es sabida la Constitución Política de 1858 estableció el régimen federal en nuestro país, lo que originó la segmentación entre el Código de Comercio marítimo (común para todos los estados) y el Código de Comercio terrestre (propio de cada estado). Tanto esta Constitución como la de 1863

Tanto la Constitución de 1858 como la de 1863 , le otorgaron la potestad a los Estados para legislar sobre materias civiles, comerciales y penales, quedando reservado al gobierno central, el comercio marítimo, exterior y costanero.

La Constitución de 1886 abolió el feudalismo restableciendo a Colombia como una República unitaria con un gobierno central, se llevó a cabo una unificación de la legislación nacional, dentro de la cual estaba la normatividad mercantil. Como resultado de lo anterior, preside de forma unificada el Código de Comercio de Panamá y el Código Nacional sobre comercio marítimo del año 1884.

A partir de este momento la legislación en materia comercial tuvo una gran variedad de leyes modificadas, pero no fue sino hasta 1968 que se conforma un comisión que trabajó hasta el año de 1971 para la creación del actual Código de Comercio colombiano, cuya expedición se dio con el Decreto Ley 410 de $1971^{9}$. Éste código tiene por objeto regular las relaciones mercantiles, aunque desde su promulgación ha sufrido diferentes reformas que debido a su época de promulgación, necesita de la adecuación y modernización en la materia.

Ya propiamente tratando el tema societario en Colombia se ha dicho que La ley 222 de 1995

9 Colombia. Decreto 410 de 1971. Código de comercio. Leal Pérez Hildebrando. Editorial Leyer. 2012. 
es un antecedente importante de la SAS, pues en ella se incluyó el novedoso régimen de la empresa unipersonal de responsabilidad limitada. Posteriormente, dentro de la ley relativa a la cultura del emprendimiento (ley 1014 del 2006) se introdujo el primer sistema colombiano de sociedades unipersonales, cuya derogatoria parcial fue el artículo 46 de la ley 1258 de 2008. Por lo que se hace necesario determinar cada régimen en Colombia antes de la implementación de la SAS.

\section{Empresa unipersonal de responsabilidad limitada}

La ley 222 de $1995^{10}$ permitió que se iniciara un proceso de modernización del Derecho Societario Colombiano. La implementación en el sistema económico local de la empresa unipersonal de responsabilidad societaria instituyó un avance significativo en la noción de las formas de empresa. Al consentir la personificación de un sujeto unipersonal, se produjo el quebrantamiento del fundamento intocable de la pluralidad de individuos para que conformen sociedad y como condición oa la limitación de la responsabilidad del constituyente. Al lado de este avance, se introdujeron conceptos novedosos escasamente difundidos en Colombia hasta entonces, tales como el objeto indeterminado, el término indefinido de duración y el allanamiento de la personalidad jurídica de la sociedad, entre otros. Igualmente aconteció un avance en la en la flexibilización del proceso de constitución de las empresas, al permitir su formalización mediante documento privado inscrito en el registro mercantil.

En la ley 222 del 1995 se reconoció una realidad económica que ya venía rigiendo en Colombia de tiempo atrás, motivada por la presencia de sociedades simuladas en las cuales la concurrencia real de aportaciones y gestión era de carácter unipersonal. Con los parámetros contenidos en esta ley se adquirió una posición intermedia entre la estricta postura contractua- lista y la concepción contemporánea de la sociedad unipersonal.

Según la corte constitucional: "en Colombia, la existencia de la sociedad unipersonal genero un gran escepticismo inicial porque se consideraba impropio de la teoría de las sociedades y de la tradición jurídica del contrato societario (art 98 del código de comercio), la inclusión en nuestra legislación de este tipo de figuras que hablaban de sociedades con un solo socio"11. Pese al escepticismo, la ley se aproximó significativamente al ideal que hoy plantea la sociedad por acciones simplificada, mediante la regulación de un mecanismo empresarial en el cual se incorporaron algunas de las más modernas postulaciones del derecho Societario.

La figura societaria implantó en la legislación colombiana trascendentales cambio de concepción, referentes a instituciones consideradas inmodificables en nuestra tradicional doctrina mercantil.

Lo cierto es que este modelo societario que además de ser útil para los pequeños empresarios, también ha servido de punto de partida hacia la modernización del sistema, al allanar el camino para la admisión de la sociedad por acciones simplificada. Esta tuvo una gran acogida y un gran crecimiento lo que generó la formalización de la actividad empresarial un beneficio tangible, tanto para el Estado como para terceros, Tanto así que en poco más de una década esta figura se convirtió en la segunda forma empresarial en importancia numérica por encima de las sociedades anónimas, en comandita y colectivas.

\section{Sociedad Unipersonal o Pluripersonal en la Ley de Fomento a la Cultura del Emprendi- miento}

El artículo 22 de la ley 1014 de $2006^{12}$ permitió la constitución de pequeñas empresas societarias de naturaleza unipersonal, eso fundamentado en las ventajas al pequeño empresario de la

\footnotetext{
10 Colombia. Diario Oficial de Diciembre 21de 1995, Ley 222 de 1995 Ley por la cual se modifica el libro primero del código de comercio, se expide un nuevo régimen de procesos concursales y se dictan otras disposiciones.

11 Sentencia C-624, 4 de noviembre de 1998, MP. Alejandro Martínez Caballero.

12 Colombia. Diario Oficial deenero de 2006, Ley 1014 de 2006
} 
flexibilidad normativa de los articulo 71 y 72 de la ley 222 de 1995, allí se propuso la superación definitiva del requisito de pluralidad al menos para las sociedades de pequeñas dimensiones. Sin embargo, la ley 1014 solo se les aplica a las microempresas o sea las sociedades cuya planta de personal no supere los 10 trabajadores, y el monto de activos sea inferior a $500 \mathrm{smlmv}$. Esta norma sólo se les aplica exclusiva a las nuevas sociedades o sea a las sociedades que se crean con posterioridad a la entrada en vigencia de la ley 1014.

Esta ley permite que una sociedad comercial, cualquiera que sea su tipo, pueda valerse del régimen contenido en la ley 222 de 1995 en materia de empresas unipersonales de responsabilidad limitada.

La finalidad de la ley fue la de facilitar e incentivar la creación de nuevas unidades de explotación económica ya que en la exposición de motivos se dejó claro que se pretendía el fortalecimiento de procesos de trabajo asociativo y en equipo en torno a proyectos productivos con responsabilidad social, además que se orienta a fomentar la formalización de los empresarios, mediante la inducción de una figura de la unipersonalidad. La norma presenta ventajas, al permitir una continuación de la supresión de formalidades para la constitución del sujeto empresario y la reducción de costos relacionados con su constitución y reformas.

Así por primera vez en Colombia se abrió paso la idea según la cual la creación de la sociedad podía cumplirse, bien por medio de un contrato, o bien de un acto unilateral, pues esta ley permitió la creación y funcionamiento de verdaderas sociedad unipersonales.

Finalmente debe aclararse que las sociedades unipersonales constituidas al amparo de dicha disposición tendrán un término máximo improrrogable de 6 meses, para transformarse en sociedades por acciones simplificadas. Esto es una simplificación del sistema, al exigir la unificación de estructuras societarias unipersonales. Así las cosas no se justifica el mantenimiento de dos sistemas que cumplen propósitos semejantes.
Entonces la importancia de la ley 1014 radica en que de forma contundente se debilita la tesis contractualista que aún prevalece en Colombia, se moderniza el régimen societario, se abre el camino para la supresión definitiva del requisito de pluralidad y se facilita la actividad de los microempresarios

\section{Sociedad colectiva}

Se trata de una sociedad externa, debido a que opera y responde frente a terceros como una persona distinta a la de sus socios, y realiza actividades mercantiles o civiles bajo una razón social unificada, respondiendo los socios de las deudas que no pudieran cubrirse con el capital social.

Ésta tiene como rasgo principal el hecho de que la responsabilidad por las deudas de la sociedad es ilimitada. Esto significa que en caso de que su propio patrimonio no sea bastante para cubrir todas las deudas lo que normalmente la llevará a un procedimiento concursal (quiebra, suspensión de pagos o similares) los socios deben responder con su propio patrimonio del pago de las deudas pendientes a los acreedores.

\section{Sociedad en comandita}

Es una sociedad de tipo personalista que se caracteriza por la coexistencia de socios colectivos, que responden ilimitadamente de las deudas sociales y participan en la gestión de la sociedad, y socios comanditarios que no participan en la gestión y cuya responsabilidad se limita al capital o comprometido con la comandita.

Se componen por dos categorías de socios, gestores o colectivos quienes comprometen de manera solidaria e ilimitada su responsabilidad y tiene la administración de la sociedad y por otro lado los comanditarios cuya responsabilidad se encuentra limitada al monto de sus aportes.

Respecto a la responsabilidad de los socios se caracteriza por ser mixta, ya que este tipo de sociedad se conforma entre socios que son responsables de manera solidaria e ilimitada, y socios que responden solo hasta el monto de sus respectivos aportes, los socios que son 
responsables de manera solidaria e ilimitada se denominan socios gestores o colectivos y los de responsabilidad hasta el monto de sus aportes se llaman socios comanditarios.

\section{Sociedad limitada}

Es una sociedad capitalista de carácter mercantil con responsabilidad jurídica, integradas por las aportaciones de socios y valoradas económicamente. Así las cosas, en este tipo societario la responsabilidad está limitada al capital aportado, y por lo tanto, en el caso de que se contraigan deudas, no se responde con el patrimonio personal de los socios.

Tipo de contrato social en donde los socios comprometen su responsabilidad en forma limitada a los aportes que al capital de ellos hayan realizado. Con excepción en material laboral y tributaria, la sociedad dentro del cual el capital social no haya sido íntegramente pagado y la no identificación de la sociedad con limitada sobrevaloración de aportes en especie.

\section{Sociedad anónima}

En ésta los titulares son en virtud de una participación en el capital social a través de títulos o acciones. Las acciones pueden diferenciarse entre sí por su distinto valor nominal o por los diferentes privilegios vinculados a éstas, como por ejemplo la percepción de un dividendo mínimo. Los accionistas no responden con su patrimonio personal de las deudas de la sociedad, sino únicamente hasta la cantidad máxima del capital aportado. Existen sociedades anónimas tanto de capital abierto como de capital cerrado. Es una figura societaria considerada para grandes empresas, tiene el carácter de abierta, puede cotizar en bolsa de valores.

\section{Sociedad de hecho}

Ésta no se constituye por escritura pública, se constituye por medio de un contrato meramente consensual sin solemnidad alguna. El registro mercantil es obligatorio y se debe realizar den- tro del mes siguiente a la constitución o permiso de funcionamiento de la misma.

Se considera como una sociedad peligrosa debido a que realiza negocios de hecho, aunque los socios tienen responsabilidades ilimitadas y solidarias por las operaciones sociales.

\section{DIFERENTES MIRADAS SOBRE LA SAS}

Realizado la anterior descripción histórica de las SAS a nivel latinoamericano y nacional en materia comercial, es necesario enfocar el tema objeto del presente escrito, lo que determina tratar propiamente el tema de la Sociedad por Acciones Simplificada en Colombia.

Como se señaló, Colombia tenía la concepción arraigada y permanente de la concepción de constituir sociedad como un contrato, esto se evidencia en el actual Código de Comercio, debido a que su artículo noventa y ocho describe el contrato de sociedad de la siguiente forma:

"Por el contrato de sociedad dos o más per-
sonas se obligan a hacer un aporte en dinero,
en trabajo o en otros bienes apreciables en
dinero, con el fin de repartirse entre sílas uti-
lidades obtenidas en la empresa o actividad
social obtenidas en la empresa o actividad
social obtenidas en la empresa o actividad
social"13.

Se percibe la noción de la sociedad como un acto que requiere la voluntad de varias personas, ya que determina en su postulado que es necesario el acuerdo de dos o más voluntades para constituir sociedad, sin embargo como se dijo anteriormente esta noción se amplió con la entrada en vigencia de Ley 22 de 1995 que consagra la creación de la Empresa Unipersonal, reforzando esta idea la Ley 1014 de 2006.

La creación de la SAS en Colombia consideró los antecedentes societarios del Derecho Societario en el país y las innovaciones del Derecho comparado. En lo que se refiere a la legislación colombiana, respecto de régimen de las socie-

$\overline{13 \text { Colombia. Decreto }} 410$ de 1971. Código de comercio. Leal Pérez Hildebrando. Editorial Leyer. 2012. 
dades unipersonales de responsabilidad limitada, impuso un gran avance, debido a la incorporación de múltiples figuras del derecho estadounidense. Con la implementación de la empresa unipersonal se avanzó hacia la configuración de un régimen societario relativamente autónomo, aunque ligado al Código de Comercio.

Respecto al Derecho extranjero reveló como las nuevas modalidades asociativas tiene rasgos relativamente similares, a los regímenes anglosajones, como por ejemplo el Estadounidense, en conjunto con el de varios regímenes europeos, lo que demostró los beneficios de adoptar un estilo de sociedad híbrido para Colombia.

Debido a que la sociedad por acciones simplificadas del sistema francés, el cual desarrolla aspectos del Derecho Estadounidense, por lo que se consideró que era más factible efectuar las reglas implementadas en Francia al estilo Estadounidense. Lo anterior debido a la cercanía del régimen francés frente al sistema societario local, con corrientes más tradicionales, lo que acepta el trasplante de figuras provenientes del Derecho de los Estados Unidos, de tal forma sería más fácil traer las innovaciones, después de haber pasado estas por el Derecho continental. Las normas que sirvieron de gran utilidad se incluyeron en el articulado, fueron sometidas a un proceso de adaptación al régimen societario vigente en Colombia.

Se buscó que el articulado tuviese un lenguaje acorde a la legislación y que tuviera concordancia con otras disposiciones legales colombianas en materia de sociedades y el Derecho Comercial Social. De igual forma. Se consideró que la Súper Intendencia de Sociedades (jurisdicción especializada en materia societaria), podría asumir facultades jurisdiccionales de naturaleza especial, para resolver conflictos surgidos en la sociedad por acción simplificada, de tal forma que se hicieran más técnicos los procesos especializados en la vigencia de la ley.
Conforme a lo anterior, la Sociedad por acciones simplificada fue creada mediante la Ley 1258 de $2008^{14}$, y ha sido considerada como un importante avance dentro del derecho societario en Colombia. Este modelo societario tiene su génesis de Francia "la Société par ActionsSimplifiées" de la ley del 3 de enero de $1994^{15}$, como se ha venido mencionado, y sin duda ha sido fuertemente implementado en Europa, toda vez que ha sido transcrito conforme a sus necesidades a diferentes normatividades latinoamericanas agregando al modelo societario iniciativas inspiradas en la legislación francesa.

"Fue concebida como una sociedad de sociedades, de carácter cerrado y régimen eminentemente flexible (contractual), para facilitar la colaboración entre empresas de grandes dimensiones con vistas a la creación de filiales comunes." 16

Su gran acogida en diferentes países se debe a que este tipo societario posee como principal característica una libertad amplia en su reglamentación, tal particularidad ha sido justificada por muchos, debido a la creciente necesidad que ha surgido en los países en desarrollo de prestar a los pequeños y grandes societarios e inversionistas un sistema flexible que se acomode fácilmente a las exigencias particulares de cada uno de ellos, como un amplio margen de control sobre el capital que se invierte en la sociedad, la administración tanto de sus negocios como del manejo de su sociedad y del aspecto tributario, del cual nos ocupamos más adelante.

Esta flexibilidad se puede evidenciar con la determinación o no del objeto social pues el único requisito que exige la ley es que sea licito, tal como se evidencia en el concepto de la superintendencia de sociedades $\mathrm{N}^{\circ} 220-160673$ “... Es enteramente discrecional de los asociados acoger según su conveniencia y necesidad, un objeto social determinado o indeterminado...".

14 Diario Oficial No. 47.194 de 5 de diciembre de 2008, Ley 1258 de 2008.

15 Francisco Reyes Villamizar, SAS La sociedad por acción simplificada. EditorialLegis.2009. Bogotá, Colombia.

16 Fabián López Guzman, La sociedad por acciones simplificada (SAS) Un Modelo Estratégico Empresarial. Ediciones Doctrina y Ley LTDA. 2012. Bogotá, Colombia. 
Se da como justificación que los tipos societarios creados en décadas o años atrás no ofrecen tal flexibilidad, puesto que el contexto en el que fueron instituidos con relación a la economía no tenían tanto afán o importancia en atraer capital extranjero ni en expandirse fácilmente, en tal sentido en épocas pasadas no se encontraba el desarrollo económico y societario que hoy se presenta, el cual busca un modelo societario que se acomode a los requerimientos de cada empresa sin importar su naturaleza ${ }^{17}$.

En el mismo texto se menciona que "la empresa capitalista colectiva alcanza su más completa extensión en la sociedad por acciones, que no es ya una unión de personas sino una fusión de capitales."18“Una de las características más importantes de la SAS es la amplísima libertad contractual propia de esta nuevo tipo. En un sistema jurídico caracterizado por la reverencia apenas retórica del postulado de la autonomía de la voluntad privada."19

En lo que atañe a Colombia la Ley 1258 de 2008, se fundamentó en la facilidad de crear empresa en el país, y así lograr inversión extranjera, que dejara como consecuencia el mejoramiento del empresario nacional, tanto a nivel interno como externo, de tal forma se ha evidenciado la proliferación de la SAS, por su facilidad de creación.

Conforme a lo anterior se hace necesario ahondar en la fundamentación de la mencionada Ley, y que mejor que hacerlo desde su definición dado que en su artículo tercero determina que "la Sociedad Por Acciones Simplificada es una sociedad de capitales cuya naturaleza será siempre comercial, independientemente de las actividades previstas en su objeto social." ${ }^{20}$ Desde otro sentido en lo que se refiere a su estructura y composición, que inicia con el trámite de su constitución que puede realizarse mediante un documento privado, sin acudir a una notaría, lo que hace más fácil su constitución y genera más posibilidades de propagación. Como es de conocimiento cada tipo societario exige un mínimo y un máximo de socios, pero la SAS no exige tal condición, por lo que un solo socio puede crearla o varios sin límite numérico, siendo entonces ilimitado.

En esa ideología se evidencia la libertad en cuanto a que este tipo societario es una sociedad de capitales y de naturaleza puramente comercial $^{21}$, independientemente de las actividades previstas en su objeto social, lo que denota simplemente en actividades licitas sin especificación mayor, es decir, que pueden desarrollar cualquier actividad comercial, entonces el objeto social puede ser indeterminado, lo que la faculta para realizar cualquier actividad lícita, siempre y cuando sus actividades no se encuentren delimitadas en los estatutos.

En lo que concierne a la personería jurídica se adquiere una vez realizado el registro en la Cámara de Comercio del domicilio de la sociedad. Junto con lo anterior se suma que el término de duración puede ser indeterminado, a diferencia de los demás modelos societarios que deben tener un tiempo de duración definido.

Hasta este punto es de vital importancia referirse a la responsabilidad de los socios, en virtud estos sólo responden hasta el monto de sus aportes, excepto en los casos de fraude a la ley o abuso del derecho en perjuicio de terceros, en lo demás sólo responden conforme a sus aportes, sin importar la naturaleza de la situación que se presente, de la cual pueda que no se alcance a cubrir con el monto de los aportes.

En lo que se refiere al capital de la SAS este se encuentra conformado por acciones de distinta clase, y los socios tienen la posibilidad legal de crear toda clase de acciones, sin que se les imponga algún límite, en virtud de la libertad contractual que ofrece la Ley 1258 de 2008. A

17 Ibídem.

18 Brunetti, 2001, pág.153.

19 Fabián López Guzman, La Sociedad por Acciones Simplificada (SAS) Un Modelo Estratégico Empresarial. Ediciones Doctrina y Ley LTDA. 2012. Bogotá, Colombia.

20 Luis Alfonso Iriarte, Sociedad por Acciones Simplificada (S.A.S.). Collage Editores SAS. Pág. 7. 2011. Bogotá, Colombia.

21 Colombia. Decreto 410 de 1971 . Código de Comercio, artículos $1^{\circ}$ y $10^{\circ}$ 
razón de lo anterior las acciones pueden ser de diferentes clases y series como a bien lo dispongan lo accionistas. .

Dentro de otro punto la SAS pueden transferir sus títulos de participación mediante un documento privado, sin mayor trámite, como la constitución de estas; ensuscripción y pago del capital se puede hacer en plazos, condiciones y proporciones decididos por los socios, sin exceder el plazo de pago de dos años.

Los conflictos que se presenten al interior de este modelo societario se resuelven ante la $\mathrm{Su}-$ perintendencia de Sociedades mediante el trámite del proceso verbal sumario, el cual se tramita de forma escrita, en audiencias dependiendo de la cuantía., en el caso en que no se pacte el arbitramento o la amigable composición en los estatutos sociales, entonces la solución de los conflictos no se deja a la justicia ordinaria, si no que se buscó mecanismos menos dilatadores para la solución de conflictos ${ }^{22}$.

De tal forma se ha definido a la sociedad por acciones simplificadas como la solución a las necesidades económicas, toda vez que es un mecanismo societario que facilita el intercambio económico en las integraciones comerciales, que se crea como persona jurídica, cuya naturaleza deber ser de carácter comercial, la cual puedededicarse a múltiples actividades, como ya se mencionó, lo que genera una amplitud comercial y productiva.

Al respecto la Corte Constitucional en uno de sus pronunciamientos indica que "al introducir en el derecho colombiano este nuevo tipo de sociedad, el legislador se inspiró en la necesidad de enriquecer el menú de opciones societarias disponibles con una modalidad basada principalmente en principios de flexibilidad y agilidad, con énfasis en la autonomía de la voluntad, y por tanto, reduciendo al mínimo las disposiciones legales imperativas, creando así, en comparación con los regímenes societarios del Código de Comercio, un espacio más am- plio para la libertad de configuración societaria basada en la voluntad de los intervinientes. Asimismo, es claro que este modelo societario avanza en el proceso de superación del enfoque contractualista que fundamentaba las modalidades societarias tradicionales - que se había y a comenzado a abandonar con la creación de las empresas unipersonales de responsabilidad limitada (Ley 222 de 1995), y las sociedades unipersonales (Ley 1014 de 2006)-, toda vez que permite que las SAS sean constituidas por una sola persona natural o jurídica, y creadas por tanto mediante acto unilateral" 23 .

De igual modo la Corte concluye en su manifestación que "la nota característica de las SAS es que crea una sociedad por acciones, pero simplifica todos los procesos de creación, administración y supresión de la sociedad. El esquema propuesto en la Ley 1258 de 2008 se basa en un principio de intervención mínima por parte del legislador, de modo que los accionistas están facultados para delinear la sociedad que más les convenga a sus propósitos, dentro de los límites contenidos en la propia ley"24.

Desde otra perspectiva se reconoce la facilidad y flexibilidad que brinda la sociedad por acciones simplificada al régimen societario, pero de igual forma se evidencia lo complejo que resulta trasladar figuras extranjeras a nuestra legislación y más al conformar un esquema social, puesto que este modelo societario deviene de un país con un avance y una evolución importante en todas sus áreas, tanto culturales como económicas y comerciales, lo que podría generar un choque en el régimen al enfrentar modelos societarios ya desarrollados con modelos societarios en desarrollo.

No obstante, lo expuesto no resulta ser lo más preocupante del tema, sino, el mal uso que se le está dando a esa flexibilidad societaria, debido a que actividades económicas aparentemente normales sirven de resguardo para ocultar acciones o movimientos ilícitos ${ }^{25}$. Estas situaciones devienen de tiempo atrás en la que personas

\footnotetext{
22 Diario Oficial No. 47.194 de 5 de diciembre de 2008, Ley 1258 de 2008.

23 Corte Constitucional Sentencia 014 de 2010.

24 Ibídem

25 Colombia. Ley 599 de 2000. Código Penal, artículos 323 y s.s..
} 
utilizan como fachada la constitución de empresas debido a su facilidad de creación y el bajo control al que son sometidas para lavar dinero origen de actividades ilícitas.

Algunos comerciantes y otros, ingresan al mundo del comercio mezclando capital lícito con ilícito creando empresa, es así como tienen el control sobre ella. Y lavando su dinero producto del delito, de tal forma los bienes de origen delictivo se integran al sistema económico legal, con apariencia de haber sido obtenidos de forma lícita ${ }^{26}$.

Precisa advertir que la ductilidad, la blandura $\mathrm{y}$ el extenso margen de manejo con el que han sido dotados los socios para operar y estructurar a sus empresas o sociedades ha traído como consecuencia la evasión de impuestos, entre otras irregularidades ya mencionadas, como por ejemplo existen empresas que argumentan generar puestos de trabajo y activos como algo nuevo y positivo para no pagar impuestos, como renta, así elevan los salarios aparentemente y de tal forma no se hacen retenciones, puesto que todo ingresa como activos y se purifica todo para no tener que pagar tributos al Estado ${ }^{27}$.

“Así las Dirección de Impuestos y de Aduanas Nacionales, DIAN, a través de sus directivos, han expresado en diversos foros públicos y privados una gran preocupación por el uso que le pueda estar dando a la SAS en el mercado para utilizarlas como herramienta de evasión fiscal. Esta preocupación, que sin duda resulta legítima y más aún desde la perspectiva de quienes tienen a su cargo recaudar los tributos colombianos." 28

Otra situación que aparece es la evasión de la seguridad social y la salud a los empleados como data el diario el Espectador "en días pasados, la DIAN y el Ministerio de Hacienda revelaron que de 240.000 empresas que se acogieron a beneficios tributarios de la ley de primer empleo, sólo el 3\% pagan seguridad social a sus trabajadores $^{29}$ ".

Lo cierto es que han surgido muchas irregularidades en Colombia, en torno a las SAS. Se han creado muchas empresas de papel para realizar actividades ilícitas o para hacer que estas se vean como actividades licitas y para evadir de manera fraudulenta los impuestos que por ley les corresponde pagar.

Habría que decir también que dado el caso en que una SAS entre en disolución y liquidación, y esta no haya cancelado sus las obligaciones tributarias, laborales y las ordinarias a favor de proveedores y terceros por que superan los activos, mientras no exista fraude ni abuso del derecho, no son los socios los llamados a responder con su patrimonio. Ley 1258 de 2008 establece plenos beneficios a favor de la empresa o sociedad y de sus socios, por lo que los verdaderos afectados con tal situación serían los terceros, lo que da como resultado la inseguridad jurídica respecto de las SAS.

En otro sentido, el socio y los socios constituyen varias sociedades por acciones simplificadas con el propósito de obtener incentivos, según lo cual sólo es viable el otorgamiento de un incentivo por cada proyecto, de igual forma el Decreto 626 de $1994^{30}$ una misma persona no puede ser beneficiaría de más de un incentivo dentro de un periodo de doce meses. Por lo demás existen otros límites respecto del incentivo para cada proyecto, así que el objetivo es eludir las restricciones establecidas en la legislación colombiana. Sin dejar de lado la evasión de impuestos a los que son sometidos a través de la ley ${ }^{32}$.

26 El diario el país de Cali. Artículo El nuevo ‘portafolio’ de la mafia para lavar dólares. Cali, Colombia.

27 El Espectador. Artículo Sociedades evasoras. 01 Abril de2012. Bogotá, Colombia.

28 Felipe Guerrero de las Casas, Sociedad por Acciones Simplificada (SAS) Novedades, Aciertos y Desaciertos. Grupo Editorial Ibañez.

2012. Bogotá Colombia. Pág. 59.

29 El Espectador. Artículo Sociedades evasoras. 01 Abril de2012. Bogotá, Colombia.

30 Diario Oficial de Colombia No. 41281, de 22 de Marzo de 1994, Decreto Reglamentario 626 de 1994.

31 Francisco Reyes Villamizar. Periódico Ámbito Jurídico, Supersociedades no tolerará abusos en las SAS. 28 de Octubre al 10 de Noviembre de 2013. B Felipe Guerrero de las Casas, Sociedad por Acciones Simplificada (SAS) Novedades, Aciertos y Desaciertos. Grupo Editorial Ibañez. 2012. Bogotá Colombia. Pág. 59. 
Lo anterior aclara que la SAS son sociedades aparentemente de baja escala y de bajo patrimonio, que con el tiempo logran un gran crecimiento financiero, ya sea que devenga de forma lícita o ilícita, con una estructura de difícil control, lo que hace que se preste para abusos, por parte de sus socios.

\section{CONCLUSIONES}

Es clara la evolución normativa en materia societaria a nivel latinoamericano, estos debido a que diversos países buscan lograr una adecuada implementación de un modelo societario flexible que cubra las necesidades y parámetros de los empresarios conforme a su esquema legal y productivo, pues no sería lógico ir en retroceso o en su defecto estancarse en un modelo societario demasiado formalista que no permita la inversión empresarial y el crecimiento integral.

Con los cambios normativos a lo largo de la historia se ha modernizado el derecho comercial, lo que permite la actualización en este ámbito conforme a los cambios sociales, implementando la reducción de los requisitos y los límites a los empresarios, de tal forma logrando romper esquemas arcaicos adoptados de forma permanente, esto ha permitido que la actividad societaria se adapte a nuevas realidades, disminuyendo en gran medida la reglamentación que se derivan en los tipos societarios tradicionales.

Resulta notoria la novedad generada en el país sobre la implementación de este modelo societario, en primer lugar porque que exige menos formalidades para la constitución de la SAS, haciéndose más económico y práctico para los empresarios, pero lo que más resalta es la posibilidad que otorga el modelo en cuanto a la amplia autonomía de la voluntad, ya que podría decirse que las normas establecidas para las SAS son de aplicación supletoria cuando falte la voluntad de las partes o del único socio. Evidenciándose que las Sociedades por Acciones Simplificadas buscan disminuir la normatividad y los procesos para la constitución de empresa, buscando en tal sentido agilizar el método para constituir una sociedad, dando potestades de autonomía y libertad a quienes determinan acoger, transformarse e implementar este modelo societario.

Este tipo societario tiene una abierta disposición por parte de sus socios, lo que da vía para la creatividad empresarial. Es así, que a partir de la entrada en vigencia de la Ley 1258 se ha evidenciado una proliferación de SAS no sólo porque las que son constituidas sino porque otros modelos tradicionales se transforman en estas tal como lo estipula la ley. No obstante, esta propagación de SAS y la flexibilidad del sistema deja como resultado la desprotección en relación con los derechos de los trabajadores, debido a que no están obligados a responder sino hasta el monto de sus aportes, buscando así sólo promover el avance empresarial, desprotegiendo por otro lado a los trabajadores y colocando en dificultades a la DIAN ya que se evidencia que en muchas ocasiones la flexibilidad de las SAS han generado la proliferación de ilicitud y para esta entidad se le dificulta mantener un control exhaustivo sobre las mismas.

Se puede anotar que la sociedad por acciones simplificadas por ser un nuevo tipo societario de capital, por acciones, con autonomía y tipicidad definida, con normas de carácter dispositivo que permiten una amplia libertad y autonomía contractual en la redacción y disposiciones del contrato social para garantizar que las relaciones jurídicas entre los accionistas sean como ellos lo deseen.

Al final de la investigación es necesario anotar que las SAS, como popularmente se les reconoce, comprenden en sí mismas una libertad, que las personas de mala fe convierten en "libertinaje" para hacer fechorías, pues al no tener límite en su objeto social ni duración en el tiempo la hace más atractiva para delinquir.

El Espectador. Artículo Sociedades evasoras. 01 Abril de2012. Bogotá, Colombia.

Diario Oficial de Colombia No. 41281, de 22 de Marzo de 1994, Decreto Reglamentario 626 de 1994.

Francisco Reyes Villamizar. Periódico Ámbito Jurídico, Supersociedades no tolerará abusos en las SAS. 28 de Bogotá. Colombia. 
Es cierto e importante resaltar que si se logro un avance en el derecho comercial en Colombia a partir de la creación de este tipo societario, que a su vez se ve reflejada a nivel Latinoamericana porque los pequeños y medianos empresarios ya están expandiéndose, no es menos cierto que en Colombia los avances casi siempre se han copiado de otros países.

Estas sociedades están siendo utilizadas para cometer delitos tales como el lavado de activos entre otros, debido a su flexibilización y a su bajo control por las entidades encargadas de este, haciéndose imposible debido a su multiplicación. Sin dejar de lado que sólo responden igualmente hasta el monto de sus aportes en materia fiscal, lo que deja como la posibilidad la realización de fraudes a la nación. Siendo lo anterior solo un abrebocas a una problemática que necesita reestructuración inmediata o en su defecto medidas efectivas que llenen estos vacíos jurídicos y que eliminen o limiten la utilización de este modelo societario para fines contrarios a la ley.

\section{REFERENCIAS}

Brunetti, 2001, pág.153.

Colombia. Constitución Política. Editorial Leyer. 2013.

Colombia. Decreto 410 de 1971. Código de comercio. Leal Pérez Hildebrando. Editorial Leyer. 2012.

Colombia. Ley 599 de 2000. Código Penal Colombiano. Editorial Leyer. 2012.

Colombia. Corte Constitucional Sentencia 014 de 2010.

Colombia. Diario Oficial No. 47.194 de 5 de diciembre de 2008, Ley 1258 de 2008.

Colombia. Diario Oficial de diciembre 26 de 1995, Ley 232 de 1995.

Colombia. Diario Oficial deenero de 2006, Ley 1014 de 2006.

Colombia. Diario Oficial de Agosto 18 de 199 Ley 527 de 1999. Por medio de la cual se define y reglamenta el acceso y uso de los mensajes de datos del comercio electrónico y de las firmas digitales, y se establece las entidades de certificaciones y se dictan otras disposiciones.

Colombia. Diario Oficial de Diciembre 21de 1995, Ley 222 de 1995 Ley por la cual se modifica el libro primero del código de comercio, se expide un nuevo régimen de procesos concursales y se dictan otras disposiciones.

Colombia. Diario Oficial de Colombia No. 41281, de 22 de Marzo de 1994, Decreto Reglamentario 626 de 1994.

Colombia. Estatuto Tributario 2009 al 2014.

Colombia. El diario el país de Cali. Artículo El nuevo ‘portafolio’ de la mafia para lavar dólares. Cali, Colombia.

Colombia. El Espectador. Artículo Sociedades evasoras. 01 Abril de2012. Bogotá, Colombia.

DE LAS CASAS. Cubreros Felipe. Sociedad por Acciones Simplificada (SAS) Novedades, aciertos y desaciertos. Grupo Editorial Ibañez. Bogotá Colombia. 2012.

Francia. Ley del 3 de enero de 1994. 
GUZMAN. López, Fabián. La Sociedad por Acciones Simplificada (SAS) Un Modelo Estratégico Empresarial. Ediciones Doctrina y Ley LTDA. Bogotá, Colombia. 2012.

UPARELA. Iriarte, Luis Alfonso. Sociedad por Acciones Simplificada (S.A.S.) Collage Editores SAS. Bogotá, Colombia. 2011.

VILLAMIZAR. Reyes, Francisco. SAS La Sociedad por Acción Simplificada. Editorial Legis. Bogotá, Colombia. 2009.

IRIARTE. Luis Alfonso, Sociedad por Acciones Simplificada (S.A.S.). Collage Editores SAS. Pág. 7. 2011. Bogotá, Colombia.

Ley $N^{\circ} 10.406$ del 10 de enero de 2002 (Código Civil). Contiene disposiciones sobre los contratos que se pueden extender a los contratos de propiedad intelectual.

Felipe Guerrero de las Casas, Sociedad por Acciones Simplificada (SAS) Novedades, Aciertos y Desaciertos. Grupo Editorial Ibañez. 2012. Bogotá Colombia. Pág. 59.

El Espectador. Artículo Sociedades evasoras. 01 Abril de2012. Bogotá, Colombia.

Diario Oficial de Colombia No. 41281, de 22 de Marzo de 1994, Decreto Reglamentario 626 de 1994.

Francisco Reyes Villamizar. Periódico Ámbito Jurídico, Supersociedades no tolerará abusos en las SAS. 28 de Octubre al 10 de Noviembre de 2013. Bogotá. Colombia.

El diario el país de Cali. Artículo El nuevo ‘portafolio’ de la mafia para lavar dólares. Cali, Colombia.

El Espectador. Artículo Sociedades evasoras. 01 Abril de2012. Bogotá, Colombia.

El diario el país de Cali. Artículo El nuevo ‘portafolio’ de la mafia para lavar dólares. Cali, Colombia.

Sentencia C-624, 4 de noviembre de 1998, MP. Alejandro Martínez Caballero 
